\title{
Adapting, DisRupting, and Resisting: How Middle School Black Males Position Themselves in Response to RACIALIZATION IN SCHOOL
}

\author{
CARL E. JAMES
}

\begin{abstract}
Studies of Black students' schooling experiences and educational outcomes have consistently shown that compared to their peers, they - especially males - tend to underperform academically, be more athletically engaged, and be streamed into non-academic educational programs. These studies tend to focus on high school students, but what of middle school students: is the situation any different? Using a combination of critical race theory and positioning theory, this article presents the results of a 2018 focus group of middle school male students residing in an outer suburb of the Greater Toronto Area. The findings reveal how the nine participants positioned themselves, and were positioned by their teachers, for an education that would enable them to enter high school and become academically successful. Some participants felt that teachers had constructs of them as underperformers, athletes, and troublemakers; others believed teachers saw them as 'regular students' and treated them accordingly by supporting their academic and extracurricular activities. How these students read educators' perceptions of them informed their positioning responses: some adjusted and others resisted. Our findings highlight the urgent need to support Black students in culturally relevant ways during the transition schooling years so that they enter high school ready to meet the social, academic, and pedagogical challenges they will face, graduate, and realize their post high school ambitions.
\end{abstract}

Keywords: Black; African Canadians; Boys; Middle-school; Stereotyping; Equity; Positioning theory; Critical Race Theory (CRT)

Résumé Les études portant sur les expériences et les résultats scolaires des élèves noirs ont toujours démontré que ceux-ci - surtout les garçons - ont tendance à présenter un rendement scolaire inférieur, à être plus portés vers le sport et à être plus souvent dirigés vers des programmes éducatifs non universitaires que leurs pairs. Ces études portent souvent sur les élèves du dernier cycle du secondaire ( $9^{\mathrm{e}}$ à $12^{\mathrm{e}}$ année). Cependant, qu'en est-il des élèves de cycle intermédiaire ( $6^{\mathrm{e}}$ à $8^{\mathrm{e}}$ année)? La situation est-elle différente? Combinant la théorie critique de la 
race (critical race theory) à la théorie du positionnement, cet article présente les résultats d'un groupe de discussion tenu en 2018 avec des élèves noirs de cycle intermédiaire résidant dans une banlieue située à l'extérieur du Grand Toronto. Les résultats révèlent comment les neuf participants se positionnent et sont positionnés par leurs enseignants, afin d'accéder à une éducation qui pourra leur permettre d'arriver au dernier cycle du secondaire et de réussir à l'école. Certains participants ont exprimé que les enseignants avaient des idées préconçues d'eux comme étant des élèves sous-performants, des sportifs et des perturbateurs; d'autres croient que les enseignants les perçoivent comme des " élèves normaux » et qu'ils les traitent comme tels en les soutenant tant sur le plan scolaire que parascolaire. La manière dont ces élèves perçoivent la perception de leurs enseignants façonne leur réponse par rapport au positionnement : certains s'ajustent, d'autres résistent. Les résultats soulignent le besoin urgent de soutenir les élèves noirs de manières culturellement pertinentes lors de leurs années de transition scolaire afin qu'ils arrivent au dernier cycle du secondaire prêts à faire face aux défis sociaux, scolaires et pédagogiques, qu'ils obtiennent leur diplôme et qu'ils réalisent leurs ambitions après le secondaire.

Mots clés: Noirs; Afro-canadiens; garçons; école intermédiaire; stéréotype; équité; théorie du positionnement; théorie critique de la race

\section{INTRODUCTION}

In writing of the "love-hate relationship" with Black males in American society, Ladson Billings noted that "no cultural form is more marketable than Black male youth culture" such as their style, their clothes, and tattoos (2011: 9). But Ladson Billings also noted that while their culture is seductive and intriguing, Black male youths are nevertheless seen as "problems" that society must find ways to eradicate: they are considered the root cause of most problems in schools and society. "We seem to hate their dress, their language, and their effect. We hate that they challenge authority and command so much social power. We seem convinced that if they wouldn't act so... 'Black,' they would not be a problem" (ibid.: 9). These perceptions are likely to be concerns during middle school: a time when "students 'try on' various identities and make important decisions about their anticipated career paths" (Musto 2019: 389). Middle school is also the time when students transition from the child-centred environment of elementary school with only one teacher to schools with "departmentalized courses, multiple teachers, and larger student populations... the time when they are looking for deeper relationships with peers and adults" (Lozier 2013: 6-7). Lozier's 2013 study of how middle school Black male students perceived effective teachers revealed that 
participants were highly attuned to the fairness of teachers and that they respected and valued teachers who held them to high standards, because this was consistent with the high expectations of their families. Essentially, these students wanted teachers who would hold them accountable for rigorous academics and provide them with the opportunity and support to meet those expectations.

The article presents the findings of a 2018 focus group of Black male middle school students, which was intended to explore their schooling experiences, how they positioned themselves, and how they were positioned by their teachers and parents for their high school years. Specifically, the focus group investigated:

(a) the high school and career plans of participants and the supports they received from important others;

(b) their perceptions of teachers' constructs of them as Black students;

(c) the extent to which they adapted to the schools'/teachers' constructs of them; and

(d) the ways in which they resisted their schools'/teachers' constructs of them.

The findings highlight the need to support Black students during the middle school years, because this transitional period positions them for life in high school, graduation, and post high school achievements.

\section{Context}

\section{Black youth schooling experiences}

Studies have long shown ${ }^{1}$ that compared to their peers, Black students in the Greater Toronto Area - especially males - tend to have poor academic performance, to be stereotyped as being more interested in sport than academics, to be streamed into non-academic educational programs, and to lack the credentials to apply to and enter postsecondary institutions (Briggs 2018; Dei and Kempf 2013; James 2012; James et al. 2017; Taylor in press). Further, a recent study reported that Black students are among the least likely to enter university, and that only about $50 \%$ of those who do enter university go on to graduate

1. Starting as far back as the 1970s, the Toronto School Board collected data on students, and the Every Student Survey was introduced in the 1980s. Reports have consistently yielded the same results for Black students - unsatisfactory school engagement and low educational outcomes (James et al. 2017). 
(Davies, Brown and Chakraborty 2019). Given this context, it is critical to examine and address the obstacles that prevent Black students from receiving the education and support - particularly in their early and transitional years - that will nurture their potential, build on their abilities and skills, and enable them to realize their ambitions.

Educational performance during the middle school years is foundational to the high school programs into which students are streamed or placed, and is also critical to later educational, occupational, and social achievements. In this regard, the schooling life of middle school students must be a constant concern. Most schools have embraced the pervasive neoliberal discourse of individualism and merit, but in reality, the educational achievements or successes of Black youth do not depend solely on hard work, commitment, and persistence (or those of their parents). The schooling structure (school policies, programs, rules, and practices), the academic and extracurricular opportunities provided, and how students and parents interact with teachers and administrators all shape schooling processes and educational outcomes. These outcomes are also shaped by the purposeful strategies used by parents and other important others (e.g., choice of residence and/or school) to ensure that their children attend a "good school" with caring teachers, ${ }^{2}$ and thereby obtain an education that sets them up for successful life in adulthood (Rollock et al. 2011)

\section{Equity, race, and education}

Structural inequity, racism, and racialization within society and the school system have been linked with isolation, surveillance, and demoralization among students. Many Black students find schools to be alienating spaces where teachers have low expectations of them and make little or no attempt to ensure that educational curriculum, pedagogy, and materials are inclusive or relevant to their experiences (Dei and Kempf 2013; James et al. 2017). Furthermore, the ongoing formal and informal practices of streaming (Galabuzi 2014), lack of diversity among teachers (James et al. 2017), the absence of support around rac-

2. This focus group was conducted with students who reside with their parents in a fairly new suburban area of the Greater Toronto Area. Suburban life and the newness of their community and school were not explored, but the decision to live in the suburbs might be considered, to paraphrase Lacy (as quoted in Rollock et al. 2011: 1081), a purposeful, instrumental strategy employed by Black parents to reduce the probability of discrimination that they and their children are likely to face in public interactions with White strangers. Further, for immigrant families, living in the suburbs might reflect upward social mobility and middle class status, which they expect school personnel to recognize. 
ist incidents in school (Maynard 2017), and the disproportionately punitive disciplining of Black students (McMurtry 2009) contribute to the challenges Black youth face in school and to their inadequate schooling and educational opportunities and outcomes. These experiences make students feel that teachers do not respect who they are and/or do not know how best to support their success in school (Taylor in press). Consultations with community members, parents, students, and educators throughout the Greater Toronto Area revealed that racial stereotyping of Black students contributed to racial stratification in classrooms, with many Black students concentrated in Applied and Essentials programs of study, as well as in special education and behavioural classes; in comparison, their White and other racialized peers were concentrated in Academic programs of study and in gifted classes. Black students also reported being treated differently in than their non-Black peers in school classrooms and hallways (James et al. 2017).

Black students generally experience a schooling system in which a "web of stereotypes" (Howard 2008) operates to racialize and marginalize them by structuring their learning process, social opportunities, life chances, and educational outcomes (James 2012). The following discussion presents the findings of a focus group exploring the experiences of Black middle school students, specifically how they negotiate and navigate a school system that continues to be inattentive to their needs, interests, expectations, and aspirations. It explores how critical race theory can unmask, disrupt, challenge, and change racial inequities that are maintained by prevailing notions of fairness, merit, colourblindness, and neutrality in institutions (Howard 2008; Milner 2008). Positioning theory is also used to analyze the narratives of the group (Allen 2017).

\section{Conceptual Framework: Positioning Theory and the Schooling OF BLACK Youth}

In an earlier article, I argued that Black young men are among the most "at risk" students because of their over-representation in special education classes, disengagement from the educational process, poor academic performance, and high rates of absenteeism, suspensions, expulsions, and dropout due to school pedagogical and disciplinary policies and practices (James 2012). This situation is maintained through the ignorance of educators, or their refusal to acknowledge, the ways in which race and racism operate in the gendered construction of Black students. Basically, the stereotypes of Black males as immi- 
grants, fatherless, athletes, troublemakers, and underachievers frame perceptions and discourses related to these youth, and in the process, contribute to the very educational and social problems that the at-risk identification is intended to address (James 2012).

Allen (2017) argued that within a White hegemonic society, Black males engage in masculinities that involve a particular intersection of raced and gendered discursive practices, which pathologize Black males as hypermasculine, deviant, hypersexual, intellectually inferior, and uneducable. He also argued that teachers of Black males are generally White, middle-class, and female, and that they regularly draw upon dominant pathologizing discourses when thinking about, interacting with, and talking about their Black male students. Black males will either adapt to or resist this conceptualization by society and teachers either taking up dominant assumptions of their identity or repositioning themselves to push back against hegemonic discourses. Investigations of these acts of positioning can help clarify how Black male students respond to the assumptions of educators and peers about them as individuals and students.

Positioning theory is related to the historical and cultural processes, interactions, and practices that place individuals into different identity categories, roles, or narratives, and how individuals may take up such identities or reposition themselves in relation to imposed roles and dominant ideologies (Allen 2017). How, when, and why Black students respond to constructions of them or assumptions about their aptitudes and capabilities as students will depend on context, timing, their sense of agency, as well as opportunities - i.e., "positioning events" presented to them. Some of them might simply accept that teachers and others see them as unable to perform at an academic (or socially acceptable) level that will lead to success in school. They might go through school living up to expectations and thereby mirror the prevailing constructs of them in their own attitudes, behaviours, and academic work.

As a result, what appears to be students "fitting" the stereotypical academic deficit profile might in fact be resistant positioning, e.g., using their interest in and desire to play sports as a reason to attend school or be in classes. The irony is that in so doing, the actions of these students might be used by educators as evidence of their views about them, rather than as a contestation of stereotypes (James 2012). Other Black students might resist stereotypes by diligently applying themselves to their academic work, satisfied that they do not have to do anything extra to be educationally successful; they may believe that they are just as good as any of their peers and do not have to prove anything. Still other Black students may resist the negative social and edu- 
cational constructions of them by working harder to prove that this is not the case; they may expect teachers to be responsive to their requests for educational supports, and be more likely to seek out opportunities, activities, or events that can reverse the negative perceptions of Black male students. Additionally, these acts of resistance may involve a byproduct: affecting how they become known to teachers and administrators. Given the subjective nature of how and when schooling policies and practices are enforced, educators might even change their ideas about Black students.

Some critical race theorists have explored the array of unrecognized and unacknowledged capital, i.e., the cultural knowledge, skills, abilities and contacts or "community cultural wealth" that racialized students bring into their classrooms from their homes and communities (Yosso 2005). Yosso identified six forms of capital - aspirational, navigational, social, linguistic, familial, and resistant capital - upon which students draw while going through school. One study of resilience and use of capital to transform school failure among African-Caribbean male high school students revealed that a major source of aspirational capital was the desire to transform their "failing" identity through a process of recovery and redemption or what could be called a "turnaround narrative" (Harding 2010) that involves recognizing previous errors and avoiding people or places that have contributed to past problems (Wright et al. 2016). The same study revealed that high parental aspirations, combined with children's desire to live up to these expectations served as a critical buffer against the reproduction of racial inequities in educational attainment, in turn creating the conditions for future possibilities. Overall, students' capital, nurtured by the social and cultural knowledge, skills, and abilities they gain from their communities and parents, plays a critical role in how students position themselves in terms of their attempts and/or desire to change perceptions of them, overcome adversities, and pursue educational possibilities for success in school.

The following sections present the research methodology, discuss the high school, educational, and occupational plans of participants, and then explore two tactics - adaptive and resistant - participants used to respond to the prevailing social and educational profile of Black students. 


\section{Methodology}

The focus group was conducted in 2018 to explore the experiences of Black male students in a middle school located in an outer suburban residential area populated by largely racialized people. The selected school has a population of more than 800 students in grades $6-8$, and the composition of these students mirrors the community. The focus group included nine self-identified Black boys aged 12-14: two each in grades 6 and 7, and five in grade 8. With the exception of one student with Trinidadian-born parents, all participants either self-identified as Jamaican or had Jamaican-born parents. They all played at least one sport mostly basketball - and were members of the school team. The school also had a Boys' Club, ${ }^{3}$ and seven of the participants were members. The boys had all gained membership in the club or on sport teams through application and teacher recommendations. The fact that all participants were involved in clubs and sport activities in their school can be partially explained by their comments that they are all friends because they share the same background:

Sid: Well people from the same race could relate, like familywise.... 'Cause we're all people of colour.... Most of our parents are born in Jamaica so like we can relate to that and stuff like that.... You can fit in more with them [each other].

Marc: I just think that we happen to be friends with people of the same race.

Sid: I don't think its intentional, but it happens without, like, you even noticing.

A case study approach is useful for this type of inquiry because it enables in-depth empirical investigation of a contemporary phenomenon in a real-world context, especially when the boundaries between the phenomenon and context may not be clear (Yin 2013). The focus group methodology was selected to capture how students constructed meaning and interpreted their interactions with others. Social scientists accept that individuals create meaning and make sense of their world not through isolation, but through social interactions with others (Liamputtong 2011; Madriz 2003; Patton 2015). Therefore, it is important to

3. Some of the Club's activities included having invited guest speakers from the community, going on field trips, and attending Board-organized student conferences. 
reduce the power imbalance in relationships between researchers and participants and thereby create "shared stocks of knowledge" (Holstein and Gubrium 1995). This is particularly essential when undertaking research with disenfranchised people and communities because it helps to facilitate a "collective voice" in the "process of writing history and culture together" (Madriz 2003: 373). Additionally, the voices of young teenagers are often absent from the narratives that researchers tell of their schooling, educational, social and cultural lives, so it is important to address this gap by recording and reporting what they say in their own words. When possible, the following discussion includes the voices of participants, who represent a population from whom we rarely hear - and consequently about whom we know very little.

In addition to facilitating participants' social construction of meaning (Liamputtong 2011; Holstein and Gubrium 1995), focus groups provide researchers with access to the evolution of perceptions in a social context (Patten and Newhart 2018) and the subjective meanings individuals attribute to their activities and environments (Flick 2009). They can also foster protected and trustworthy spaces for participants to share their stories, especially after meeting others with similar experiences that set them apart from others (Barbour 2007). This approach is consistent with the principles of critical race theory, because it provides opportunities for racialized and marginalized people to be empowered and share their perspectives. It can also lead to the emergence of counter stories against the colonizing or racist discourse, which constantly reproduces negative images of Black youth (Madriz 2003).

I facilitated the focus group with two research assistants (one male and one female) who live in the area. All three of us are Black, and our shared racial identification likely signaled to participants that we have a level of familiarity with their lived experiences. It is likely that the information we received from participants was limited - at some level the findings might be considered "partial truth" (Clifford 1987) - but our similarities and insider attributes helped us gain insights and develop a counternarrative based on their telling of their lived experiences. The focus group interview lasted for about 1.5 hours. It was conducted at the school with students who volunteered, with permission from teachers and parental consent. We began by introducing ourselves to the students, and then asked them to tell us their name, grade, something about their ethnic/racial background, and their hobbies (e.g., what sport they play). Next, we asked them to tell us about their experiences at school - with teachers, peers, the principal, and other school staff. We also asked about their educational and occupational/career interests and 
aspirations, what high school they planned to attend, and how well they were doing in getting to their life goals.

The focus group was audio-taped, transcribed verbatim, coded, and analyzed. The three facilitators exchanged the transcription, separately identified recurring major and minor themes, and then met to discuss our respective answers, noting commonalities and differences as we cross-referenced the identified themes. The following discussion focuses specifically on the experiences of participants and their high school plans. Five of them were to enter high school in three months (the coming fall), and two in the following year. With high school approaching, they needed to be thinking about and deciding on their educational and occupational path after high school. To ensure anonymity, pseudonyms were given to participants, the school, and any teachers, parents, or other individuals participants referred to. The research protocol was approved by the York University Office of Research Ethics.

\section{Results}

\section{Getting ready for high school: The educational and career plans of participants}

Most participants said they would attend the high school into which their elementary school fed, but were not sure about which program level (advanced, general, essential/locally developed) they would choose. Of the five students who were to enter high school the following fall, two planned to go to a Catholic school. ${ }^{4}$ One of them would be attending the same school as his older sister (as his mother insisted), and the other wanted to go there because of its basketball team. Two other students wanted to attend a public school with a good reputation in sport, even though their middle school didn't feed into it, and it was some distance from their homes. Kian said, "I want to play on a good team for basketball." This kind of interest in sport is consistent with that of many Black males, who may use sport to navigate and negotiate their way through school, and may use sport to obtain scholarships to colleges and universities - especially in the United States (James 2016). Some participants said their parents encouraged these aspira-

4. We learned that Black parents are increasingly sending their children to Catholic School - most often secondary school, even though the children attended public elementary schools. This was likely based on the perception that their children would be in a more disciplined school environment where they would receive a "better" education. 
tions and supported their choice of high school based on sport. For example, Kian explained that his mother agreed to him attending his chosen high school because "she wants me to continue playing sports." He added: "basketball is my favourite sport... I'm really good at it. I've been playing it since I was young." He said he planned "to see if I can get into a college league; and see if I can get into the NBA." In contrast, Jamie said he was being "forced" to attend the same high school as his sister even though he wanted to attend the reputable "sport school" like Kian, which would mean travelling about twenty more minutes from home. When asked if he had discussed his interest with his parents, he said he had, and that his mother's response was: "You're still going!"

Interestingly, only Kian spoke of pursuing a career in sport - possibly because the others thought that a career in sport, especially basketball, would likely be out of reach. Marc, a grade 6 student, said that he is "going to be a lawyer like my mother;" and Jamal, a grade 7 student, planned to become an electrician with the hope of taking over the family business once his grandfather passes his company to him and his brothers. Anthony, a grade 8 student, said that he planned to become an engineer or "a business person." Although most participants shared their aspirations, few talked about their grades - and only two said that they are getting good grades. Silence about grades or educational and career plans might reflect a tempered approach to education. Allen (2013) observed that some Black males avoided drawing attention to their academic success out of fear that they would be judged by peers as not being "cool" enough. Nevertheless, many focus group participants seemed to have put effort into their academic work to satisfy their obligations to their parents - from whom they got the message that, as Sam said: "You need school to get the job you want.... School is important.... I need to do my work...I need to keep up with what I am doing in class." Other participants, like Marc, made comments like: "My mom is constantly on my case about school." Adam said that when he did not provide his parents with a satisfactory answer to how he was doing in his school work, his mother would say that she will "have conversations with the teacher to keep tabs on me."

Participants said that for the most part, their school, curriculum, and other educational materials were not culturally relevant or responsive to their learning needs, interests, and expectations. When asked if they learned "anything about Black people in their classes" - particularly things that would help prepare them for high school and life thereafter - the general consensus was "No." Sam said: "Well, the only class time we usually talk about Black folks is during Black history 
month" which, as some participants pointed out, a few teachers brought up, but "only for a short period." Furthermore, the few Black "leaders" they were able to recall from what they covered in school were the usual non-Canadian personalities - Martin Luther King and Nelson Mandela. ${ }^{5}$

Overall, the middle school did not provide participants with the necessary educational scaffolds (culturally relevant educational materials and a schooling environment that captures their imagination and interest in academic work over sport) that would prepare them for an academic high school program (James et al. 2017). As a result, they may be unable to take advantage of educational, occupational, career and social opportunities in the future and fulfill their ambitions. Awareness of their potential limits in education will play a significant role in their positioning tactics as they negotiate school.

\section{Perceived constructs of Black students: "A lot of them are stereotyp- ical"}

Participants commented that teachers and peers - particularly their nonBlack peers - had perceptions of them as athletes, disrupters, troublemakers, lawbreakers, and/or just "regular students." We asked: "How are you thought of by your teachers and peers?" After a chorus of sighs, we heard comments including:

Tre: They have negative things to say.

Jay: Well, a lot of them are stereotypical.... They just think that we all play basketball... [referring to their peers]. They think that we all eat chicken. They make jokes like you go to KFC - that's all we eat.

Marc: That's true, because I hear it from...

Several participants completed Marc's sentence, saying that they heard "these things from other teachers and students." Underscoring how widespread negative notions of Black students are in his school, Jay said: "They might not say it, but you can tell that they are thinking it.

5. It is possible that Canadian leaders were mentioned in classes, but the fact that none came immediately to mind is likely a reflection of the dominant narratives that have been passed onto them by their school, media, and other sources. It is worth noting that this focus group was held only months after the introduction of the new ten-dollar bill featuring Viola Desmond, yet even she did not come to mind. 
How they are looking at you and like: 'Basketball again?' And they make comments like that or something."

Jaden went on to relate an experience in his class in which his friend - of whom he said, "He's not bad" - was talking to him while he was trying to listen to the teacher. According to Jaden, he "got in trouble" because the teacher thought Jaden "was not paying attention" and was talking to his friend instead. In explaining why he likely got into trouble even though he "was listening to the teacher," while his "friend was looking at [him] and talking," Jaden said: "Because I'm Black." This perception of Black students as insubordinate or lacking discipline was also illustrated in a story Jay shared about his friends:

Jay: It wasn't me, but my friends told me.... It was, like, they went up to each other and they did a handshake, right. And it was, like, a whole group of them. They were just shaking each other's hands, and like greeting each other. And then after, a teacher just came up to them - they are all people of colour... - and go: Are you guys dealing drugs or something? And then after, my friends said it made him feel bad and stuff.

Based on his own experience, Anderson added: "Say there's a group of people of colour, some teachers might think, it's like a group of troublesome kids."

Some students also drew comparisons between teachers' treatment of them and their White peers to illustrate how teachers' perceptions of them as "disrupting" students negatively affected their access to education. Here is how the discussion went:

Kian: So, this happened in grade 7. I was in French class and I didn't have a pencil. So, I was asking my friend for a pencil, and the teacher was just like: 'Why are you interrupting my class and study.' And I was just like: 'I wasn't interrupting, I was just asking my friend for a pencil.' And she like: 'Get up and go sit over there by yourself.' And I was like: 'I was just asking for a pencil what did I do?' It was Ms. Reno.

Participants collectively groaned: That's why....

Kian: I was like: 'Why should I get up and move?'... I finally got up and went to go sit over there. And then like five minutes later my White friend did the same thing but nothing happened to him.... 
Adam: Same thing happened to me with Ms. Reno. I was with some of my friends; it happened yesterday.... So, when we were all buying [food] there were just a big line...., and the bell rang when everyone was still in the line. So, we grabbed our food and went to Ms. Reno and she told us that we had to stay outside. She saw us. It was me and four of my friends who are all coloured.... She said you guys stay outside and she wouldn't let us in the class. And then after we were done and waiting, she came outside and said: 'Do you want me to call the office and say that you are refusing to come into my class.'

Participants: Wait! What? [laughing]

Adam: ....and after she said that, and then [she] made everyone go back inside.... When we were all sitting down watching the presentation, she made me and my friend come and sit beside her for some reason.

Most participants seemed to accept that the behaviour of this teacher was as expected. Their comment: "Wait! What?" was not merely a signal of surprise or disbelief that the teacher would threaten "to call the office" with a false allegation about Adam, but a cynical expression of resentment to how they are treated by teachers. By citing the race of the involved students as "all coloured," they alluded to how race, and by extension, racism, operated in the teacher's perceptions of and actions toward them - they were seen as students who "are refusing to come into my class" and hence needed to be disciplined by the ultimate power in the school - "the office."

The narratives point to constructs of participants as unhealthy eaters, athletes more than they are students, inattentive to teachers, lacking discipline, lawbreakers, and troublemakers. Some students considered these constructs to apply only to individual students and felt they had no bearing on their own schooling - from their perspective, Black students were treated like "regular students." These students adapted accordingly by acting in ways and engaging in activities and events that were consistent with schooling expectations. Others saw the constructs as inherent within the racializing school system - in resisting them, they would name the inconsistencies and inequities in the system, challenge teachers and the existing rules, and initiate measures that would serve their needs and interests. Furthermore, failing to obtain the changes they sought, they pragmatically decided to "hold it" - i.e., hold the anger in order to avoid serious consequences. The following discussion explores these two positioning approaches. 
"Regular students": Adaptive positioning and the constructs of Black students

Not all participants felt that negative perceptions were prevalent among teachers. Jamie, for example, took issue with the claims of racial profiling or stereotyping by teachers. For instance, in response to Adam's claim that the teacher would not let them into class because they were students "of colour," he said:

You can't necessarily say that without proof.... They [the teacher] didn't specifically say..., or even hint: 'Oh, you're Black so you guys have to stay outside....' So, you can't say that it's racially motivated.

He went on to argue that the teacher's behaviour is merely a reflection of the fact that "She's just a mean teacher." And while Jamie's peers sought to have him acknowledge that this teacher and others treat Black students differently, he maintained his position, saying: "I haven't been in an encounter where I was racially stereotyped." Agreeing with Jamie and pressing the idea that Black students are not treated differently to other students, Darren declared: "I think that we are perceived as regular students because I haven't encountered any stereotyping." Anthony hypothesized that teachers like Ms. Reno may have been influenced by experiences with students from previous years, and have not really recognized that they are dealing with a different group of students.

Anthony: I have a feeling that in this school - this school has like a bad past. And all that the kids did last year - some of the grades $8 \mathrm{~s}$ - teachers had bad experience with them... and so they carry that bad experience to the kids... that are going to grade 8 [who] aren't really like the kids who went to grade 9 .

The assertions of Jamie, Darren, and Anthony are likely related to the positive experiences and opportunities they have had as members of the school's Boys' Club, of which, as Jamie said proudly: "I'm the president of the boy's club." As members and leaders, these students might have been seen as exceptions to the stereotypes of Black students, and hence were able to build relationships with teachers and administrators, which may have helped to shape their views of being seen and treated as "regular students."

In building relationships with teachers, some participants accepted that teachers are people too, with feelings and fears. In another study involving high school students, one participant said:

6. It should be noted that membership in the Club is gained through teachers' recommendations. 
But I think that we as students tend to forget sometimes that teachers are also people too. Like, I'll see someone by themself; and if I'm uncomfortable, I won't go out of my way to talk to them. And with teachers, I think that we forget that they're people too and teachers may be just as uncomfortable approaching us sometimes, as we are approaching them about things (James, 2019: 14).

Thus, some focus group participants may have interpreted the negative encounters that their peers have had with teachers as personal matters that were unrelated to institutional characteristics, and to which their peers also contributed.

Relationships with teachers was significant to the schooling experiences of participants. Kian, a grade 8 student, had this to say of his homeroom and history teachers:

They were the first two teachers who really believed in me. They would always say: 'Oh [Kian], I know you can do better.' All my other teachers really did not care, but those two teachers actually cared about how well I was doing and so my mom really liked them.

Anderson, another grade 8 student, agreed, commenting:

My homeroom teacher, my math teacher, ...they give us a lot of homework; and they don't do it just for the sake of doing it; they do it to get us ready for high school.

The extent to which their teachers made efforts to build a relationship with them and worked to get them "ready for high school" was a significant factor in the students' assessment of their teachers as people who supported them and cared about their school engagement, academic performance, and educational achievements. Participants were appreciative of teachers going beyond just giving a grade on an assignment, as well as helping them to obtain passing grades, and encouraging them to pursue their interests. Stan, a grade 8 student, has this to say:

Yeah, my teacher, Mr. Tonge, like, say, if I got a mark that could have been way better, he won't just like, give me the mark or show you the mark and that's it. He'll talk to you and tell you, ... like: 'This is how you could do better.' And he won't just say how to study. He'll tell us how to organize your life so that you could have free time and study also and have a balance.

For a number of students, this "balance" meant having the opportunity to participate in extra-curricular activities, particularly sport, which many of them were able to play at school. They appreciated that their 
teachers did not assume that because they participated in sport they were merely athletes, or that their participation in sport would reduce their interest in their academic work. They liked that these teachers encouraged them in their "passion."

Anson: My homeroom teacher, she supports me, because like...back then, when I wasn't doing really well... [and] like when teachers know you want to join a team, she actually let me join the team 'cause she knows that basketball is my passion.

And Marc, a grade 6 student who had earlier criticized how Black students were stereotyped in the school, added: "I made the volleyball team; and my homeroom teacher, Ms. Skerritt, would cheer me on." Marc was clear that only "some of them" (teachers) were perpetuating stereotypes. Homeroom teachers were most likely to be identified as supportive. This is likely related to the fact that students were able to build a relationship with these teachers, who likely took the time to get to know them (and their parents) as individuals and to pay attention to their needs, interests, expectations, and aspirations (Baker et al. 2008; Hughes et al. 2001; Murray and Malmgren 2005). ${ }^{7}$

The claims of being seen as "regular students" might reflect positive feelings about relationships with teachers, and might also be a way for participants to reassure themselves that teachers are genuinely committed to their learning. The students seemed to realize that these relationships and commitments are necessary because teachers have the power to assess their academic performance and school engagement - which will determine their educational outcomes and ultimately their life trajectories. The ambivalence about teachers' racialized assumptions or profiling of Black students ${ }^{8}$ may be interpreted as adaptive tactics to a schooling process that contributes to the racialization of Black males "as culturally deficient and a 'problem' that needs to be fixed" (Allen 2017: 269).

\section{"Just have to hold it": Disrupting, rejecting, and resisting racialization}

Most participants were highly critical of teachers whom they believed did not take interest in their learning. Anderson said: "They don't really focus on us, but on the Brown students." The students understood that without deliberate, genuine support from teachers, they would not meet

7. Previous studies have also revealed that relationships with teachers are more important to students than the teachers' approaches to the subjects they teach (Garner 1995)

8. We did not find any differences in the assertions of younger and older students. 
all of the requirements to enter high school. Sam commented that his teacher "tried to get me into sports stuff instead of actually helping me with math." Participants wanted teachers to take the time to ensure that they understood what was being taught, especially when teachers were asked, as Adam did, "for more help." Adam went on to recount an experience in which he asked the teacher's permission to stay after class to talk further, but the teacher told him "to leave."

Adam: Yeah, like I'll ask, and then they'll say. 'Probably, I'm not free.' But like sometimes if they are free, they still probably won't let me stay.... If they did, I could actually understand more.

Adam alluded to the dishonesty of this teacher: like Anderson, he felt that by "not focusing on" students, and not offering them "more help" even when asked, teachers demonstrated that they were not really interested in their learning. Participants shared other experiences illustrating teachers' disrespect for them, including teachers not speaking with them directly about their educational performance and giving them poor evaluations (grades) without providing needed educational supports. Sid said that if students did "something wrong, ... some teachers won't punish you for it, but it shows up on your report card." Some participants reasoned that giving poor grades - and recording them on their report cards for their parents to see - was a punitive measure employed by teachers to give their parents a reason to punish them. They knew how seriously their parents (and others) would react to what is written on the report cards. Some were afraid of being "beaten" or having their devices taken away. As Sid commented: "I'd rather get a punishment than have it show up on my report card."

After John spoke of a similar action by a teacher, the group voiced its condemnation of the distrustful actions of teachers - referring to them as "snakes" - and offering ideas about ethical and supportive ways in which teachers should act:

John: Yeah, ... like one time in music, ...at the end of the year, my teacher gave my mom a note and told her that I failed...like, I was failing at the very end of the year.

Participants [inserting]: Yeahhh! Oh yeah that happened; Ms. Anson, right? At the very end?

Participants: [Simultaneously]: At the very end of the year.... 
John: ... when I can't do anything to improve my grade.

Adam: She sent a note home and then my mom got mad at her, she's like: 'Why is she just sending this now?' She had the whole year. She sent it at the end of the year.... [Participants interrupts] No, she sent it before.... She sent it home; but like a week before school was going to finish. So, I couldn't change my mark. And my mom got mad.

Facilitator: How do you guys feel about that?

Sam: Snakes.... She could have sent that note home a long time ago...

Sid: Exactly!

Sam: To even let you know...; to make you change your mark.

John: I didn't even know that I was failing.

Sam: She wait till the end of the year when you can't even do nothing.

John: I didn't even know that I was failing. I thought that I was doing good.

Facilitator: So, then who do you go to for support in situations like this?

Sam: You just have to hold it.

Participants [2 together]: Just hold it.... Yeah, hold it. You hold that.

Overall, students felt that teachers did not have time to help them with their academic work, were more interested in getting them "into sports," did not believe what they said and as a consequence would discipline them, and used questionable ethics to warn (rather than advise) them about their grades. They saw these actions as consistent with their own racialization and the inequitable schooling system. At no time did any of the participants label their teachers' behaviours as racist, but they did cite the race of the students involved in the incidents, noting differences in the discipline received from teachers. Recognizing that 
there is a limit to how much they are able to resist or push back against their racialization and the inequitable and unwelcoming school climate, they pragmatically concluded that they "just have to hold it" [the anger]. They also felt that eventually the "negative things" in their school will have to change: Tre commented optimistically: "there's a lot of us around ... they should get used to us in their environment."

\section{Discussion}

"Get used to us in this environment": Asserting agency, countering stereotypes

The call for teachers and their non-Black peers to "get use" to them in "their" schooling environment reflects the awareness that "school is important" and is needed to "get the job" and other opportunities for success. However, the use of the word "their" reflects the recognition that participants are yet to be accepted as part of the schooling environment, and the reference to their growing population reflects their awareness that it is up to them to collectively work toward achieving a schooling environment that is responsive to their academic needs, interests, and expectations. Participants said they were committed to doing well in their academic work; to this end, some rejected claims related to the racializing process of the school and its teachers and claimed that they are seen as "regular students." Others acknowledged that stereotypes existed and referred to experiencing discriminatory practices. Some of them stressed the need for changes to the Eurocentric school program and curriculum, which fail to address their presence as Black students, but they were still aware of the limits to their counteractions. Basically, the "aspirational capital" of many of these young men - that is, their desire to be enthusiastic about their scholastic ambitions in spite of all the barriers that stood between them and their academic success (Wright, Maylor and Becker 2016) - helped them exercise agency and position themselves against marginalization and racialization.

As expected, perceptions of teachers varied in relation to context, interest, academic subject, schooling activity, and the nature of their contact and/or relationships with teachers. Pomeroy (1999) noted that student perceptions of and relationships with their teachers are important elements of schooling and educational experiences and "are framed by a hierarchy of worth.... The criteria for determining one's position in the hierarchy are entirely teacher - and school - defined. The recognised dimensions of importance are ability and/or knowledge, and 
behavior with "more able" or "better behaved" students positioned closer to the teacher and enjoying preferential status" (Pomeroy 1999: 476). In terms of hierarchy, focus group participants noted that White and Brown students were higher in the hierarchy than Black students, who were therefore subjected to differential discriminatory treatment by teachers. Previous research has demonstrated that teachers of Black males are usually White middle-class females who often draw upon the dominant discourse of Black students being deficient when interacting with them (Schnyder 2012). This finding may help explain the difficult teacher-student relationships and differential treatment reported by participants, who complained of teachers refusing to provide academic assistance when requested; surveillance of them while other students who exhibited similar or worse behaviour went unpunished or received lighter punishment; and school reports sent to their parents without the courtesy of knowing first. Participants considered these actions to be dishonest and deceptive, calling the teachers "snakes." Allen referred to these disciplinary practices of teachers as a symbolic form of violence that "supports the social construction and positioning discourse of black masculinities in the school" (2017: 279).

How these Black students understood their position within the hierarchy of students in their school played a role in their interactions with teachers. Relationships with teachers were also fostered by their membership in extracurricular activities. In addition to sport teams, the Boys' Club was one setting that several participants credited with providing valuable skills in leadership, discipline, and responsibility as well as the visibility necessary to counter or resist dominant racial discourses regarding Black masculinity. The Club served as a means to navigate the school system, which made some participants feel like "regular students" and helped others by serving as a resource for repositioning exercises. These exercises have helped Black boys perform "black masculinities that stand against racial domination and critique the process and ideologies contributing to the overregulation, surveillance, and discipline of black masculine performance" (Allen 2017: 271).

Several participants repeatedly referred to their mothers as the parent who would: ask about their school day, insist on them doing their homework or "read a book," "have a conversation" with their teachers, threaten to call their teachers, be the ones to express their "liking" or displeasure with their teachers, support their athletic aspirations, be a model for their interest in a subject (e.g., math), be the one who tends to have a major influence on the high school they would attend, and be the parent to whom they wished the teacher would not tell about their 
bad grades or behaviour for fear of being disciplined. ${ }^{9}$ The parents of the students in this study clearly supported their children's education and were significantly engaged in their learning in a variety of ways. Previous studies have demonstrated that when raising Black children in a racist society, parents, especially middle-class mothers, tend to work hard at getting their children the supports they need to resist the dominant hegemonic portrait of Black masculinity, which frames them as "failures" or "problematic students" (Vincent et al. 2012; Wright et al. 2016). Some scholars have argued that these actions by parents should be recognized as forms of resistance as they navigate and manage racial marginalization, and in so doing "prepare their children to do the same" (Allen and White-Smith 2018: 418; see also Allen 2017; LewisMcCoy 2016; Vincent et al. 2013). One study found that Black parents of Caribbean descent in Britain deployed their class resources as a form of resistance because they "refuse to be positioned as unknowing, unworthy, and uncaring by educational institutions" (Vincent et al. 2012: 269).

\section{Conclusion}

Altogether, the findings of the study indicate that the students were well aware of the importance of education as a means to realizing their educational and social ambitions. Educators, parents, community members, and political leaders must support their aspirational capital, making every effort to provide Black male middle school students with education that effectively prepares them to meet the social, educational, and pedagogical challenges of high school and beyond. With the influence of their parents, and for some, the support of teachers, these Black students will be well-positioned to apply themselves to their education, and in the process to exercise agency and take initiatives for a successful life trajectory - including getting their teachers to be responsive to their educational needs, interests, and aspirations. These early teenagers have a very worthy ambition: to transform perceptions of them as underachievers, athletes, troublemakers, deviant, disruptive, and intellectually incompetent by working to have teachers and peers come to see them as leaders who are responsible and academically capable.

9. This was also the case in the larger study. 


\section{REFERENCES}

Allen, Quaylan. 2017. “They Write Me Off and Don't Give Me a Chance to Learn Anything": Positioning, Discipline, and Black Masculinities in School: Black Male Resistance. Anthropology \& Education Quarterly 48(3):269-283

Allen, Quaylan. 2013. Balancing school and cool: Tactics of resistance and accommodation among black middle-class males. Race Ethnicity and Education 16(2): $203-224$.

Allen, Quaylan and Kimberly White-Smith. 2018. “That's Why I Say Stay in School": Black Mothers' Parental Involvement, Cultural Wealth, and Exclusion in Their Son's Schooling. Urban Education 53(3):409 - 435.

Baker, Jean A., Sycarah Grant, and Larissa Morlock. 2008. The Teacher-Student Relationship as a Developmental Context for Children with Internalizing or Externalizing Behavior Problems. School Psychology Quarterly 23(1):3-15.

Barbour, Rosaline. 2007. Doing Focus Groups. Los Angeles: Sage Publications.

Briggs, Anthony Q. 2018. Second Generation Caribbean Black Male Youths Discuss Obstacles to Educational and Employment Opportunities: A Critical Race Counter-Narrative Analysis. Journal of Youth Studies 21(4):533 549.

Clifford, James. 1986. Partial Truths. In Writing Culture, James Clifford and George E. Marcus (Eds)., 1-26. Santa Fe, CA: School of American Research.

Davies, Scott, Robert S. Brown, and N. Chakraborty. 2019. The University of Toronto-Toronto District School Board Cohort Analysis: Introductory Findings. Toronto: University of Toronto and Toronto District School Board.

Dei, George J. Sefa and Arlo Kempf. 2013. New Perspectives on African-centred Education in Canada. Toronto: Canadian Scholars' Press, Inc.

Flick, Uwe. 2009. An Introduction to Qualitative Research. London; Los Angeles: Sage Publications Ltd.

Galabuzi, Grace-Edward. 2014. Race and the streaming of Ontario's children and youth. In David Clandfield, Bruce Curtis and Grace-Edward. Galabuzi. Restacking the Deck: Streaming by Class, Race and Gender in Ontario Schools, Special Issue. 285 - 226. Ottawa: Canadian Centre for Policy Alternatives.

Garner, P. 1995. Schools by scoundrels: The views of 'disruptive' pupils in mainstream schools in England and the United States. In Mel Lloyd-Smith and John Dwyfor Davies (Eds). On the Margins: The Educational Experience of 'Problem' Pupils, 18 - 21. London, England: Trentham Books.

Harding, David J. 2010. 'Living the drama': Community, conflict and culture among inner-city boys. Chicago: University of Chicago Press. 
Holstein, James A., and Jaber F. Gubrium, 1995. The Active Interview. Qualitative Research Methods, Series 37. Thousand Oaks: Sage Publications.

Howard, Tyrone C. 2008. Who really cares? The disenfranchisement of African American males in Prek-12 Schools: A critical race theory perspective. Teachers College Record 110(5): 954 - 985.

Hughes, Jam N., Timothy A. Cavell, and Victor Willson. 2001. Further support for the developmental significance of the quality of the teacher-student relationship. Journal of School Psychology 39(4):289 - 301.

James, Carl E.. 2019. We Rise Together: A Research Report for Peel District School Board. Toronto: J. A Chair/Faculty of Education, Faculty of Education, York University. http://www.peelschools.org/aboutus/equity/ Documents/We\%20Rise\%20Together\%20report\%20-\%20Carl\%20 E\%20James\%20June\%202019.pdf.

James, Carl E. 2016. Why is the school basketball team predominantly Black?" In E. Taylor, D. Gillborn and G. Ladson-Billings (Eds.), Foundations of Critical Race Theory in Education, 63 - 76. New York: Routledge.

James, Carl E. 2012. Students "at risk": Stereotypes and the schooling of Black boys. Urban Education 47(2):464 - 494.

James, Carl E., Turner, Tana, George, Rjonda, and Tecle, Sam. (2017). Towards Race Equity in Education: The Schooling of Black Students in the Greater Toronto Area. Toronto: J. A Chair/ Faculty of Education, York University. . https://edu.yorku.ca/files/2017/04/Towards-Race-Equity-inEducation-April-2017.pdf.

Ladson Billings, Gloria. 2011. Boyz to men? Teaching to restore Black boys' childhood. Race Ethnicity and Education 14(1):7 - 15.

Lewis-McCoy, R.L'Heureux. 2014. Inequality in the Promised Land: Race, Resources, and Suburban Schooling. Stanford, CA: Stanford University Press.

Liamputtong, Pranee. 2011. Focus Group Methodology: Principles and Practices. Los Angeles: Sage Publications Ltd.

Lozier, Francis Vladimir. 2013. Black Male Students' Perceptions of Effective Teachers: A Qualitative Study of Compton Middle Schools. University of California, Los Angeles (ProQuest Dissertations Publishing) (Dissertation/Thesis).

Madriz, Esther. 2003. Focus groups in feminist research. In Norman K. Denzin and Yvonna S. Lincoln (Eds.), Collecting and Interpreting Qualitative Materials, 363 - 388. Thousand Oaks, CAL.: Sage Publications Ltd.

Maynard, Robyn. 2017. Policing Black Lives: State Violence in Canada from Slavery to the Present. Winnipeg: Fernwood.

McMurtry, Roland Roy. 2009. The roots of youth violence in Ontario report. Education \& Law Journal 19(1):35 - 39. 
Milner, H. Richard. 2008. Critical race theory and interest convergence as analytic tools in teacher education policies and practices. Journal of Teacher Education 59(4):332 - 346.

Murray, Christopher and Kimber Malmgren. 2005. Implementing a teacher-student relationship program in a high-poverty urban school: Effects on social, emotional, and academic adjustment and lessons learned. Journal of School Psychology 43(2):137 - 152.

Musto, Michela. 2019. Brilliant or bad: The gendered social construction of exceptionalism in early adolescence. American Sociological Review 84(3):369-393.

Patten, Mildred L. and Michelle Newhart. 2018. Understanding Research Methods: An Overview of the Essentials. New York: Routledge.

Patton, Michael Quinn. 2015. Qualitative Research \& Evaluation Methods: Integrating Theory and Practice. Thousand Oaks, CAL. Sage Publications, Inc.

Rollock, Nicola., David Gillborn, Carol Vincent, and Stephen Ball. 2011. The public identities of the Black middle classes: Managing race in public spaces. Sociology 45(6):1078-1093.

Schnyder, Damien M. 2012. Masculinity lockdown: The formation of Black masculinity in a California public high school. Transforming Anthropology $20(1): 5-16$.

Taylor, Leanne .(in press). "I will treat all my students with respect": The limits to good intentions." In Carl E. James Colour Matters: Essays on the Experiences, Education and Pursuits of Black Youth. Toronto: University of Toronto Press

Vincent, Carol, Stephen Ball, Nicola Rollock, and David Gillborn. 2013. Three generations of racism: Black middle-class children and schooling. British Journal of Sociology of Education 34(5 - 6):929-946.

Wright, Cecile, Uvanney Maylor, and Sophie Becker. 2016. Young Black males: Resilience and the use of capital to transform school 'failure'. Critical Studies in Education 57(1):21-34.

Yin, Robert K. 2014. Case Study Research: Design and Methods. Thousand Oaks, CAL: Sage Publications.

Yosso, Tara J. 2005. Whose culture has capital? A critical race theory discussion of community cultural wealth. Race Ethnicity and Education 8(1):69 91. 


\section{ACKNOWLedgements}

To everyone who made this publication possible, I express my appreciation - to the guest editors, Professors Johanne Jean-Pierre and Lance McCready, the reviewers for their comments, the research assistants Beatrice Anane-Bediakoh and Andre Harriott, and Dr. Nemoy Lewis and Tka Pinnock for reading earlier drafts. I also acknowledge the funding received from Social Sciences and Humanities Research Council (SSHRC), Ontario Ministry of Advanced Education and Skill Development, Ontario Ministry of Education, and Peel District School Board.

Carl James holds the Jean Augustine Chair in Education, Community \& Diaspora in the Faculty of Education, York University, Toronto, where he is also the Affirmative Action, Equity \& Inclusivity Officer. His research interests include examination of how race, ethnicity, gender, class and citizenship intersect and affect opportunities in education and employment for Black and other racialized youth. James holds a $\mathrm{PhD}$ in Sociology. One of his most recent co-authored publications include: The Equity Myth: Racialization and Indigeneity at Canadian Universities; and a forthcoming book, "Colour Matter": Essays on the Experiences, Education and Pursuits of Black youth.

Email: cjames@edu.yorku.ca 